\title{
Effects of temperature and strain rate during hot compression of manganese aluminum bronze
}

\author{
Nuwan Wannaprawat, Akrawech Subhakom and Surasak Suranuntchai ${ }^{\text {a }}$ \\ Department of Tool and Materials Engineering, Faculty of Engineering, King Mongkut's University of Technology \\ Thonburi, 126 Pracha Uthit Road, Bang Mod, ThungKhru, Bangkok 10140, Thailand
}

\begin{abstract}
Manganese Aluminum Bronze or MAB alloy has been extensively used for applications under sea water such as marine propellers because this alloy exhibits high strength as well as excellent corrosion resistance behavior. In this work, microstructures and hardness properties of an annealed MAB alloy after hot deformation at different temperatures of $973 \mathrm{~K}$ $1123 \mathrm{~K}$ and strain rates between $0.1 \mathrm{~s}^{-1}$ and $1 \mathrm{~s}^{-1}$ were investigated. During the tests, stress-strain responses of the alloy were determined, and effects of temperature and strain rate on the flow behavior of the MAB alloy were subsequently examined. Furthermore, microstructures of deformed MAB alloy were characterized by both optical microscopy and scanning electron microscopy. Effect of microstructure on stress-strain curves was illustrated for various forming conditions. The results showed at different temperature and strain was found dynamic recovery and dynamic recrystallization.
\end{abstract}

Keywords: hot compression; MAB; temperature and strain rate effect; microstructure; mechanical properties.

\section{Introduction}

Manganese Aluminum Bronze or so-called MAB alloy has the UNS designation of C95700 and British standard designation of CMA1.This alloy has been widely used in various applications under sea water, mainly as marine propellers, because it offers many advantages like high strength, excellent corrosion resistance, good melting, cast ability, proper weld ability and nonmagnetic [1-6].MAB alloy principally contains of copper, aluminum, manganese and small additions of iron, nickel, silicon and lead. In general, MAB alloy shows heterogeneous microstructure including FCC $\alpha$ phase, BCC $\beta$ phase and small $\kappa$ phases embedded in the $\alpha$ phase matrix. At room temperature, in the microstructure of MAB alloy, higher $\beta$ phase fraction more than 50 percent could be present depending on the $\mathrm{Mn}$ content, because high concentration of Mn causes a stabilizing effect on the $\beta$ phase [1-5]. It was well observed that dealloying of such MAB alloy mostly occurred at the $\beta$ phase areas since the $\beta$ phase had the most negative electrode potential value in comparison to other phases. By corrosion tests, aluminum content of the $\beta$ phase became much lower than other uncorroded areas. In contrast, the $\alpha$ phase was found to be more corrosion resistant to seawater [4].Tang et al. [5] investigated as-received $\mathrm{MAB}$ alloy and reported that cavitation erosion was initiated at the $\kappa$ phase as well as at the $\alpha-\beta$

${ }^{a}$ Corresponding author : surasak.sur@kmutt.ac.th 
interfaces and then propagated in the matrix phase. In case of laser-treated MAB alloy, erosion started at some triple junctions and propagated along grain boundaries [5].

Extensive investigations according to dynamic recovery and dynamic recrystallization of alloys have been focused on the study of flow stress behavior under different deformation condition and microstructure evolutions by optical microscope [6-12]. Most recent works analyzed correlations between developed microstructures and stress-strain responses. Shen et al. [6] reported that stressstrain curves at high temperatures of a copper alloy exhibited a rapid stress increase to peak stress due to work hardening of material at an early state of deformation. Then, flow stress of the copper alloy slightly decreased because of material softening and eventually reached a steady flow stress at higher 2026 aluminum alloy under different temperatures and strain rates. At earlier state, dislocation multiplied dramatically and work hardening process was predominant. At the later state, the microstructure pattern was elongated grains, and small dynamically recrystallized grains were available. Amounts and sizes of such dynamically recrystallized grain depended on deformation temperature and strain rate [7].

The present work aimed to study influences of strain rate and temperature on flow stress behavior during the hot compression test. Microstructure characteristics of the MAB alloy after different hot deformation conditions were determined. The obtained results regarding phase identifications were correlated and discussed.

\section{Experimental procedures}

MAB alloy delivered as ingot material was used in this study. As mentioned, the investigated MAB alloy contained $\mathrm{Cu}, \mathrm{Al}, \mathrm{Mn}$ and small additions of $\mathrm{Fe}, \mathrm{Ni}, \mathrm{Si}$ and $\mathrm{Pb}$. The chemical composition in weight percent of the alloy was obtained from Optical Emission Spectroscopy (OES), as given in Table 1. Before hot forming experiments, the as cast MAB ingot was homogenized at the temperature of $923 \mathrm{~K}$ for 6 hours in order to obtain homogenous microstructure. Figure 1 showed the microstructure of as annealed MAB alloy. It could be seen in Figure $1 \mathrm{~b}$ that the FCC $\alpha$ phase, BCC $\beta$ phase and small $\kappa$ precipitate phases were still present altogether. After annealing, the MAB alloy exhibited decreased amount of $\beta$ phase, and $\kappa$ precipitate phase became larger than that in as-cast condition. Then, cylindrical specimens with a diameter of $5 \mathrm{~mm}$ and height of $10 \mathrm{~mm}$ were machined from the annealed MAB sample. Using deformation dilatometer, the specimens were heated up to the compression temperatures of $973 \mathrm{~K}, 1023 \mathrm{~K}, 1073 \mathrm{~K}$ and $1123 \mathrm{~K}$ with a heating rate of $10 \mathrm{~K} / \mathrm{s}$. The specimens were held at those temperatures for about 60 s for a homogeneous temperature distribution. After that, they were compressed with a constant strain rate until a height reduction of $60 \%$ was reached. In this work, two strain rates, namely, $0.1 \mathrm{~s}^{-1}$ and $1 \mathrm{~s}^{-1}$ were applied. Finally, the samples were cooled down with a cooling rate of about $2-3 \mathrm{~K} / \mathrm{s}$.

Table 1. Chemical composition (wt \%) of the investigated MAB alloy

\begin{tabular}{cccccccc}
\hline Element & $\mathrm{Cu}$ & $\mathrm{Al}$ & $\mathrm{Mn}$ & $\mathrm{Fe}$ & $\mathrm{Ni}$ & $\mathrm{Si}$ & $\mathrm{Pb}$ \\
\hline wt \% & Bal. & $\mathbf{8 . 1 6}$ & 7.54 & 2.56 & 2.36 & $\mathbf{0 . 0 3 8}$ & $\mathbf{0 . 1 5 0}$ \\
\hline
\end{tabular}

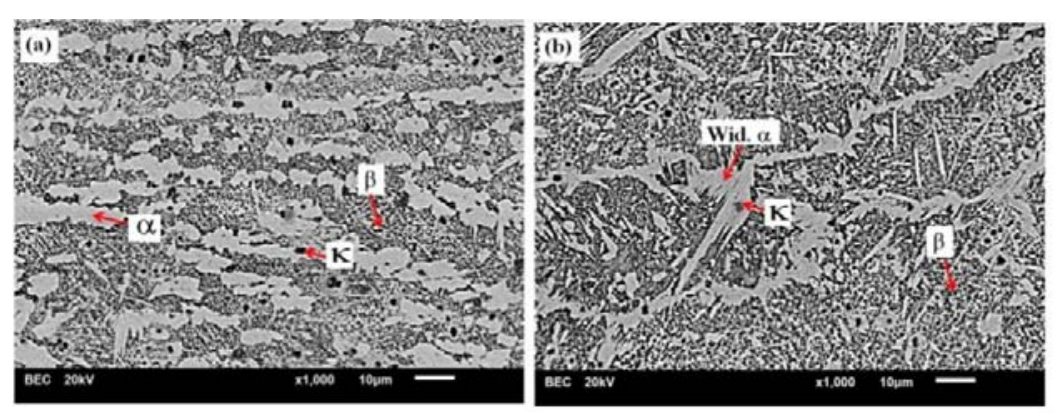

Figure 1. Microstructure of as annealed MAB alloy from (a) OM (50X) and (b) SEM (1000X) 
During the hot compression tests, stress-strain responses of the specimens were gathered for each condition. After the tests, specimens were sectioned in parallel to the forming axis for microstructure observation using Light Optical Microscopy (LOM) and Scanning Electron Microscopy (SEM).The samples were mounted, first polished with SiC paper with 2000 grit and polished by $1 \mu \mathrm{m}$ alumina at the end. Then, the samples were etched using a solution containing $5 \mathrm{~g} \mathrm{FeCl}_{3}, 5 \mathrm{ml} \mathrm{HCl}$ and $100 \mathrm{ml}$ $\mathrm{H}_{2} \mathrm{O}$ for $10 \mathrm{~s}$. Phase fraction of the $\alpha$ and $\beta$ phase were measured by the image analysis program.

\section{Results and discussion}

\subsection{Flow behavior}

The results of stress-strain curves of the investigated MAB alloy obtained during hot compression at different temperatures of $973 \mathrm{~K}, 1023 \mathrm{~K}, 1073 \mathrm{~K}$ and $1123 \mathrm{~K}$ and strain rates of $0.1 \mathrm{~s}^{-1}$ and $1 \mathrm{~s}^{-1}$ were presented in Figure 2a and $2 \mathrm{~b}$, respectively. It could be observed that the flow stresses exhibited a rapid increase at the beginning until peak stresses were reached. At this state, work hardening dominated because of dislocation multiplied dramatically. After dynamic softening had taken place, it led to an offset of work hardening effect. In other words, flow stresses decreased monotonically to higher strain because the effect of work hardening could be partially neutralized by the occurrence of dynamic softening mechanisms [8-9]. At last, the flow stresses, that gradually decreased, approached a steady state because of dynamic recrystallization during hot deformation [10]. Otherwise, flow stresses remained nearly constant after peak stress regarding dynamic recovery. This was due to the fact that dislocation gliding became much easier and balance of dislocation density was reduced [11].

For the deformation temperatures of $973 \mathrm{~K}$ and $1023 \mathrm{~K}$ at both strain rates, flow stress curves increased to maximum stress value with a single peak and then they became almost steady that indicated occurred material softening. By these flow characteristics, dynamic recovery was likely promoted. For the deformation temperature of $1073 \mathrm{~K}$ and $1123 \mathrm{~K}$ at both strain rates, while plastic strain increased, flow stress curvesrose to maximum stress with a single peak and then the flow stresses slightly dropped until a steady state was reached. These flow characteristics probably indicated dynamic recrystallization mechanism. The dynamic recovery and dynamic recrystallization will be discussed in details later by microstructure observation after hot deformation.

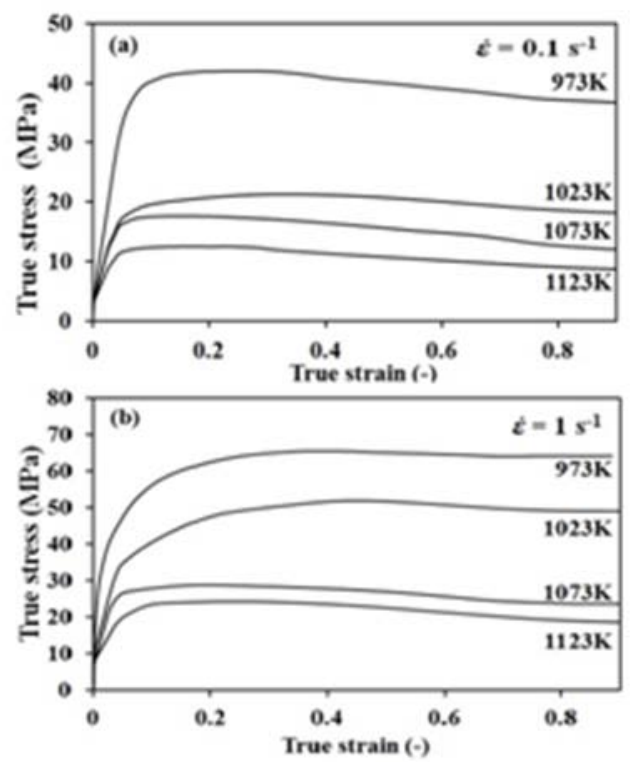

Figure 2. Obtained stress-strain curves of the investigated MAB alloy at the strain rate of (a) $0.1 \mathrm{~s}^{-1}$ and (b) $1 \mathrm{~s}^{-1}$ for all testing temperatures. 
At the same deformation temperature, peak stress increased with increasing strain rate. In contrast, the peak stress decreased with increasing temperature when considering the same strain rate. These results were in accordance with [6]. Determined peak stresses of the MAB alloy were shown in Table 2.

Table 2. Determined peak stresses of the investigated MAB alloy by different forming conditions

\begin{tabular}{ccccc}
\hline \multicolumn{5}{c}{ Peak stresses of MAB alloy (MPa) } \\
\hline \multirow{2}{*}{$\left(\mathrm{s}^{-1}\right)$} & $973 \mathrm{~K}$ & $1023 \mathrm{~K}$ & $1073 \mathrm{~K}$ & $1123 \mathrm{~K}$ \\
\hline $0.1 \mathrm{~s}^{-1}$ & 42 & 21 & 18 & 12 \\
$1 \mathrm{~s}^{-1}$ & 65 & 52 & 29 & 24 \\
\hline
\end{tabular}

\subsection{Effects of temperature and strain rate}

As seen in Figure $1 \mathrm{~b}$, as annealed microstructure of the MAB alloy consisted of $\alpha$ (FCC), $\beta$ (BCC) and $\kappa$ phase. However, microstructure of the MAB alloy sample after hot deformation at the temperatures of $973 \mathrm{~K}, 1023 \mathrm{~K}, 1073 \mathrm{~K}$ and $1123 \mathrm{~K}$ and the strain rates of $0.1 \mathrm{~s}^{-1}$ and $1 \mathrm{~s}^{-1}$ were completely altered, as illustrated in Figure 3 and 4, respectively. After compressing at the temperature of $973 \mathrm{~K}$, it was found that the MAB microstructure still contained the $\alpha, \beta$ and $\kappa$ phases. By this temperature, undissolved $\alpha$ phase remained in the final microstructure at room temperature, as clearly depicted by SEM in Figure 5a.In case of higher temperatures at $1073 \mathrm{~K}$ and 1123K, amount of the $\alpha$ phase continuously decreased, since the transformation from $\alpha$ to $\beta$ phase already took place. Nevertheless, by cooling down with the cooling rate of $2-3 \mathrm{~K} / \mathrm{s}$, the $\beta$ phase transformed again to the $\alpha$ phase and $\kappa$ precipitate. After cooling to room temperature, the MAB microstructure thus showed the $\alpha$ phase with Widmanstaetten pattern, as seen in Figure 5b. It could be stated that increasing temperature led to a higher phase fraction of the $\beta$ phase. Table 3 showed the measured phase fraction of the $\beta$ phase available in the MAB microstructure after hot deformation under various temperatures and strain rates. It was observed that amount of the $\beta$ phase slightly increased when the forming temperature was increased while the amount of the $\alpha$ phase became lower. However, no significant effect of strain rate on the phase fraction was recognized.
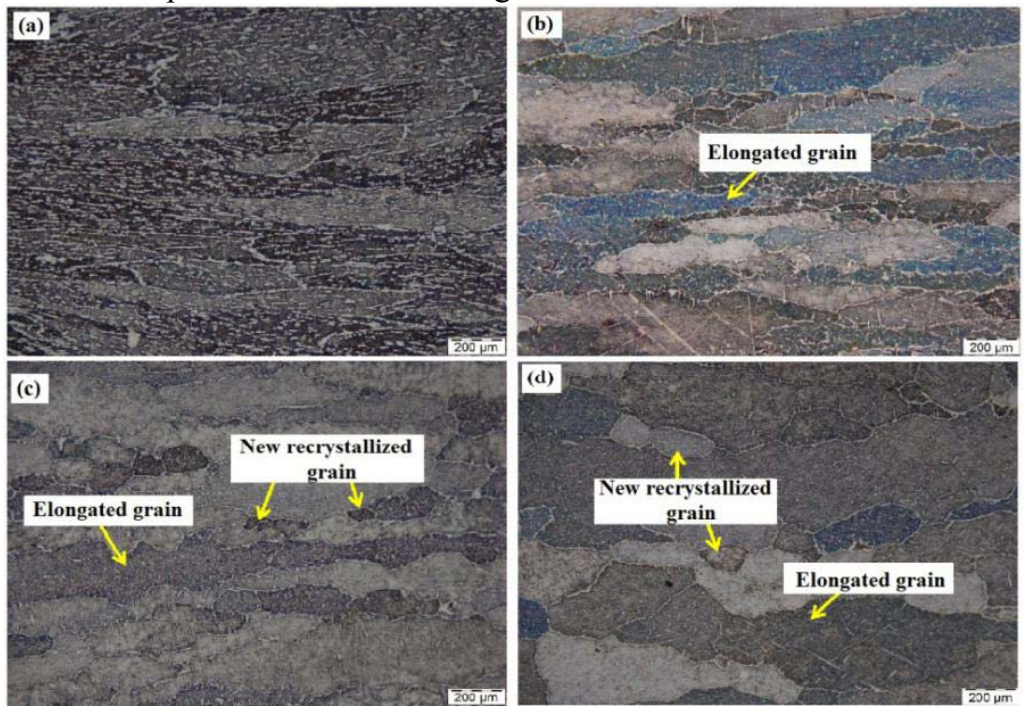

Figure 3. Micrographs of the examined MAB alloy deformed with the strain rate of $0.1 \mathrm{~s}^{-1}$ at the temperatures of(a) $973 \mathrm{~K}$, (b) $1023 \mathrm{~K}$, (c) $1073 \mathrm{~K}$ and (d) $1123 \mathrm{~K}$ 
Table 3. Determined phase fraction of the $\beta$ phase (\%) of MAB alloy after hot compression under different conditions

\begin{tabular}{ccccc}
\hline \multicolumn{5}{c}{ Fraction of the $\beta$ phase $(\%)$ of the MAB alloy } \\
\hline \multirow{2}{*}{$\left(\mathrm{s}^{-1}\right)$} & $973 \mathrm{~K}$ & $1023 \mathrm{~K}$ & $1073 \mathrm{~K}$ & $1123 \mathrm{~K}$ \\
\hline 0.1 & 80 & 87 & 92 & 94 \\
1 & 83 & 85 & 89 & 93 \\
\hline
\end{tabular}
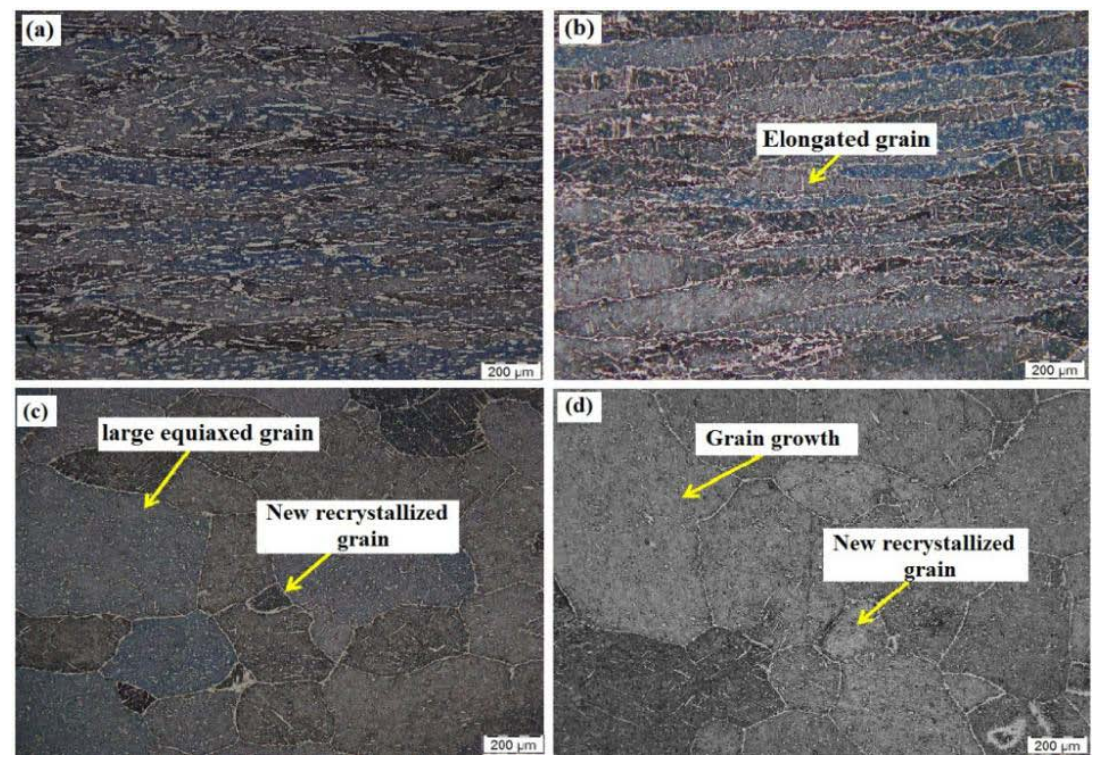

Figure 4. Micrographs of the examined MAB alloy deformed with the strain rate of $1 \mathrm{~s}^{-1}$ at the temperatures of (a) $973 \mathrm{~K}$, (b) $1023 \mathrm{~K}$, (c) $1073 \mathrm{~K}$ and (d) $1123 \mathrm{~K}$
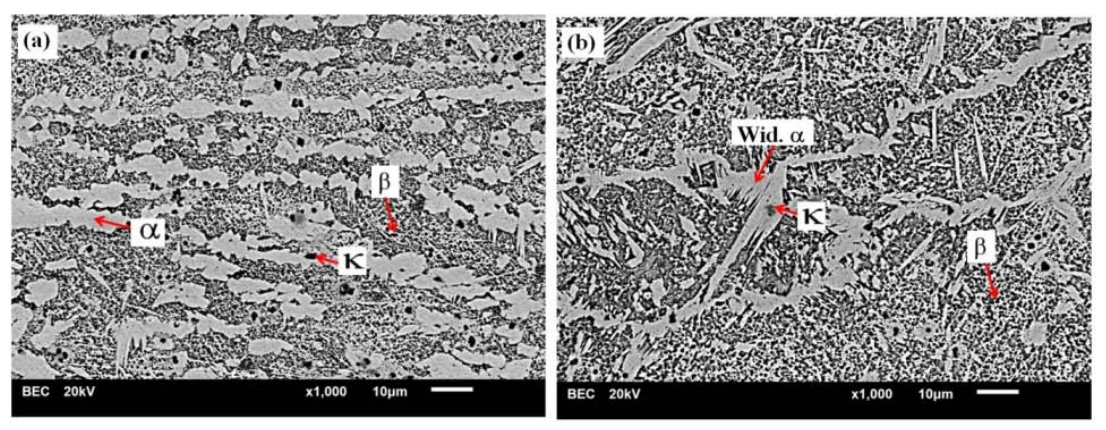

Figure 5. Microstructures of the investigated MAB alloy observed by SEM after deformation at the strain rate of $0.1 \mathrm{~s}^{-1}$ and the temperatures of (a) $973 \mathrm{~K}$ and (b) $1023 \mathrm{~K}$

The microstructure of the MAB alloy deformed at the strain rate of $0.1 \mathrm{~s}^{-1}$ and the temperature of $973 \mathrm{~K}$ was depicted in Figure 3a. Obviously, highly elongated grains along the compression direction were present. However, microstructures of the MAB alloy compressed at the temperature of $1073 \mathrm{~K}$ exhibited elongated grains with the lower magnitude and some small recrystallized grains that occurred surrounding those elongated grain, as seen in Figure $3 \mathrm{c}$. The microstructure of the MAB alloy undergoing hot compression at a high temperature of $1123 \mathrm{~K}$, as illustrated in Figure $3 \mathrm{~d}$, consisted of relatively large equiaxed grains and some hints of newly recrystallized grain. By the same manner, microstructures of the MAB alloy deformed at the strain rate of $1 \mathrm{~s}^{-1}$ and the temperature of $973 \mathrm{~K}$ and $1073 \mathrm{~K}$ clearly showed largely elongated morphologies along the compression direction. When the deformation temperature increased, small dynamically recrystallized grains could be 
recognized around grain boundaries of the elongated grains, as seen in Figure $4 \mathrm{~b}$ and $4 \mathrm{c}$. Microstructures of the MAB alloy compressed at the temperature of 1123 Kexhibited large equiaxed grain with noticeable grain growth together with few small newly recrystallized grains, as depicted in Figure $4 \mathrm{~d}$.

From the results, elongated grain structures were observed by hot compression of the MAB alloy at the lower temperatures of $973 \mathrm{~K}$ and $1023 \mathrm{~K}$. Thus, it could be stated that softening mechanism of the MAB alloy during this temperature range was dynamic recovery. On the other hand, deformation at higher temperatures such as $1073 \mathrm{~K}$ and $1123 \mathrm{~K}$, elongated grain structures vanished, but dynamically recrystallized grains occurred at grain boundaries were observed. The softening mechanism of the MAB alloy during this temperature range was, therefore, dynamic recrystallization. The amount of the recrystallized grains and their grain size increased with rising deformation temperature. During hot deformation, the alloy transformed to recrystallized structure due to high mobility of grain boundaries according to growth kinetics. As deformation temperature increased, the grain growth was apparently promoted [11].

At high-temperature range, it seemed that increasing strain rate led to larger developed equiaxed grains and decreased amount of small recrystallized grains in MAB microstructure. At the strain rates of $0.1 \mathrm{~s}^{-1}$, averaged grain sizes of 58 and $98 \mu \mathrm{m}$ were measured for the temperatures of 1073 and 1123 $\mathrm{K}$, respectively. Though, at a higher deformation rate of $1 \mathrm{~s}^{-1}$, larger averaged grain sizes of 98 and 115 $\mu \mathrm{m}$ were obtained for those temperatures. In other words, the microstructure of the MAB alloy after hot deformation at high strain rate showed a lower amount of small dynamically recrystallized grains than that at lower strain rate. This observation implied apparent suppression of dynamic recrystallization due to increasing strain rate[12]. This is likely because the severity of dislocation pile-up was increased with increasing strain rate. This temperature range promoted fully recrystallized and coarsened equiaxed grains. It could be well stated that microstructure evolution of the MAB alloy significantly depended on the strain rate [12].

\section{Conclusion}

1) For the deformation temperatures of 973 and $1023 \mathrm{~K}$ at the strain rate of $1 \mathrm{~s}^{-1}$, flow stress curves increased to a peak stress and directly reached a steady state flow stress, by which dynamic recovery took place. For the temperature of 1073 and $1123 \mathrm{~K}$ at both strain rates of 0.1 and $1 \mathrm{~s}^{-1}$, flow stress curves increased to a peak stress and then gradually dropped to a steady state flow stress at higher strain, in which dynamic recrystallization occurred.

2) By hot compression below the temperature of $1023 \mathrm{~K}$, elongated grain structures were mostly observed in the microstructure indicating that only dynamic recovery occurred. Above the temperature of $1123 \mathrm{~K}$, small dynamically recrystallized grain could be seen. Sizes of these recrystallized grains were increased with rising deformation temperature. At the high strain rate of $1 \mathrm{~s}^{-1}$, the lower amount of small recrystallized grains was found than from the strain rate of $0.1 \mathrm{~s}^{-1}$.

\section{Acknowledgements}

The authors would like to acknowledge the Researchers and Research for Industry, the Thailand Research Fund, for financial support in this project. In addition, sincere thanks must be given to the Naval Dockyard Department, Royal Thai Navy for useful advice and supporting the MAB alloy.

\section{References}

1. J. Iqbal, F. Hasan, F. Ahmad, Mater. Sci. Technol. J. 22, 6 (2006)

2. P. Wenschot, Cast Metals Res. J. Int 17(5), 257-263 (2004)

3. P. Wenschot, Int. J. of Cast Metals Research. 17, 257-263 (2004)

4. Z. Han, Y.F. He, H.C. Lin, Mater. Sci. J. letter. 19, 393-395 (2000) 
5. C.H. Tang, F.T. Cheng, H.C. Man, Surface and Coatings Technol, 182, 300-307 (2004)

6. K. Shen, M.P. Wang, S.M. Li, Alloys Compound. J. 479, 401-408 (2009)

7. X. Huang, H. Zhang, Y. Han, W. Wu, J Chen, Mater. Sci. Eng. A. 527, 485-490 (2010)

8. C. Shi, W. Mao, X.G. Chen, Mater.Sci. Eng. A. 571, 83-91 (2013)

9. H. Zhang, K. Zhang, Z. Lu, C. Zhao, Xi. Yang, Mater. Sci. Eng. A. 604, 1-8 (2014)

10. H. Zhang, H. Zhang, L. Li, Mater. Proc. Technol. J. 209, 2892-2896 (2009)

11. G.Z. Quan, D.S. Wu, G.C. Luo, Y.F. Xia, J. Zhou, Q. Liu and L. Gao, Mater. Sci. Eng. A, 589, 23-33 (2014)

12. R.L. Xin, B.S. Wang, Z. Zhou, G.J. Huang, Q. Liu, Trans. Nonferrous Met. Soc. China. 20, s594-s598 (2010) 